\title{
The impact of health care restructuring on nosocomial infections and transmission of antimicrobial resistant organisms
}

\author{
J Conly MD CCFP FRCPC FACP ${ }^{1}$, Lynn Johnston MD FRCPC ${ }^{2}$
}

$\mathrm{T}^{\mathrm{h}}$ he past decade has seen a dramatic change in Canadian health care as the treatment of many patients shifts from the hospital setting to the home or other alternative health care settings (1). Complex advances in technology and significant changes in the funding environment have also precipitated many changes in the functional capacity of our health care system. The portion of the total Canadian health care expenditures that has been allocated to hospitals and other institutions has declined steadily over the past two decades $(2,3)$. This reduction in institutional-based funding reflects the need to develop a system that improves the use of out-ofhospital sites for delivery of health care services and decreases reliance on the specific institutional component of the health care sector. Recent data reveal that Canadian hospital discharge rates have decreased by $14 \%$ between 1994 and 1998, and there has been a reduction in the length of stay from 7.4 to 7 days (4). In conjunction with a reduction in the number of hospital beds, there has been a massive shift in the proportion of surgeries that are performed on an outpatient basis. Further developments in the delivery of care include the increased use of telehealth, which allows health care professionals to provide increasingly complex services centralized hospital sites to outlying areas.

The shifts in the funding and delivery of health care serv- ices have produced an array of new and difficult challenges. First, the shift in patient care has caused an increase in the severity and acuity of illness among patients receiving care in the hospital environment compared with hospitalized patients in previous decades. These shifts have led to critical care beds. Thus, patients who now receive care in the hospital setting may be at an increased risk for a number of adverse outcomes including nosocomial infections, deep vein thrombosis, pulmonary embolism, upper gastrointestinal bleeding, central nervous system complications, decubitis ulcers, sepsis and increased transmission of antimicrobialresistant organisms. The present article briefly reviews important aspects of the restructured hospital environment and how they may contribute to an increased risk for nosocomial infections and the transmission of antimicrobialresistant microbes. In addition, relevant data that support this hypothesis are reviewed.

Several factors unique to the current restructured health care setting may contribute to an increased propensity for nosocomial infections and the transmission of antimicrobialresistant pathogens. These factors may be related to the host, the host-microbe interaction, the use of antimicrobials, the host-antimicrobial interaction, the host environment (including the physical plant, general environmental hygiene, the

\footnotetext{
${ }^{1}$ University Health Network, University of Toronto, Toronto, Ontario; ${ }^{2}$ Queen Elizabeth II Health Sciences Centre and Dalhousie University, Halifax, Nova Scotia

Correspondence: Dr John Conly, Department of Medicine, Division of Infectious Diseases, Suite 13-118 Norman Urquhart Wing, Toronto General Hospital, University Health Network, 200 Elizabeth Street, Toronto, Ontario M5G 2C4. Telephone 416-340-4858, fax 416-3405047,e-mail john.conly@cls.ab.ca and Dr Lynn Johnston, Room 5014 ACC, Queen Elizabeth II Health Sciences Centre, 1278 Tower Road, Halifax, Nova Scotia B3H 2Y9. Telephone 902-473-8477, fax 902-473-7394, e-mail ljohnsto@is.dal.ca
} 
use of aseptic technique and other infection control practices), and the host-health care provider interaction, the latter of which has received scant attention.

Patients with a higher level of acuity of illness, greater levels of immunosuppression, malnutrition, history of frequent hospitalizations, presence of invasive devices, and loss of integrity of normal skin and mucosal barriers, and a more aged population all contribute to an increased risk of infection (5-7). Immobility, bladder and bowel incontinence, and immunosenesence, often found in the elderly, are also associated with an increased risk of infection. Patients at an increased risk of infection are also more likely to become colonized or infected with antimicrobial-resistant pathogens related to exposures during previous health care encounters and have an increased exposure to antimicrobial agents, both of which may contribute to this increased risk of infection (810). Another important factor affecting nosocomial infections and the transmission of antimicrobial-resistant organisms is the facility utilization of antimicrobials $(11,12)$. Many studies have demonstrated a relationship between antimicrobial utilization and the development of resistance $(13,14)$. With an increased acuity of illness and higher burden of complex medical illnesses, it is anticipated that there will be a greater need for antimicrobial use of those patients remaining in the hospital system. A recent five-year review of antimicrobial utilization at a Canadian tertiary care institution, based on a standardized incidence density rate of usage, revealed that there has been a steady increase in the use of antimicrobials during the latter part of the 1990s (personal communication, $\mathrm{K}$ Iverson, M Pitre and J Conly).

Restructuring within the institutional setting is often associated with construction activities and the realignment of the delivery of health care services within the institution. The association of construction and renovation projects with increased propensity for infections such as Legionnaires disease and Aspergillus species infections is well documented and has been recently reviewed (15). Changes in the physical plant may also be associated with changes in the environmental hygiene and disinfection practices. These changes may include the inappropriate use of flash sterilization, unsafe handling of infectious wastes, no means of physically cohorting patients, lack of dedicated equipment, recirculation of unfiltered air and decreased environmental hygiene $(15,16)$.

Another factor that plays a role in the restructured environment is the poor use of aseptic technique and other sound infection control practices, including handwashing. Considerable evidence supports the belief that antimicrobialresistant organisms may be carried from patient to patient via the unwashed hands of health care workers (17). The larger variety of health care workers, including less skilled workers and part-time staff attending to patients needs, may result in inconsistent training and compliance with basic hygiene skills such as handwashing, gloving, gowning and the use of aseptic technique. Case control studies have demonstrated that lack of familiarity with a required skill set in a specific work setting has been associated with an increased number of nosocomial infections $(18,19)$. Concern has also been raised regarding the use of an increasing number of unregulated casual health care providers, and the impact that this may have on development of nosocomial infections and the transmission of antimicrobial-resistant microorganisms. Several studies have demonstrated that understaffing, and the educational level and skill of the health care practitioner have an association with the transmission of microorganisms and the development of nosocomial infections; these latter points deserve specific comments.

During the 1990s, repeated media reports of cutbacks in hospital nurse staffing, as well as the adverse effects of these cutbacks, on patients created a significant concern in the nursing profession of both United States and Canada. In the United States, these reports generated significant public interest and led to a Congressional hearing, a report by the Institute of Medicine and the development of a National Research Agenda within several agencies within the United States federal government. As a result of these deliberations, the Secretary of Health and Human Services requested that the topic of nurse staffing and quality of care be examined. This examination led to the Health Resources and Services Administration, Division of Nursing (within the Health Care Financing Administration) and National Institute of Nursing Research (within the National Institutes of Health) to cosponsor a massive study to investigate the relationship between patient outcomes sensitive to nursing ratios and the nursing staffing levels in acute care hospital inpatient units. The results of this 11-state, all patient analysis demonstrated strong and consistent relationships among nursing staff variables and several patient outcomes, including urinary tract infections and pneumonia rates (20). There was a very strong link between patient outcomes and levels of registered nursing staffing compared with evidence linking patient outcomes to less skilled workers. Regarding urinary tract infection rates in medical and surgical patients, there was an estimated $4 \%$ to $12 \%$ and $5 \%$ to $6 \%$ reduction, respectively, with high registered nursing staffing, and a $4 \%$ to $25 \%$ and $3 \%$ to $14 \%$ reduction, respectively, with high levels of all nursing staffing. Similarly, with respect to the development of nosocomial pneumonia in medical patients, there was an estimated $6 \%$ to $8 \%$ reduction in rates with higher registered nursing staffing and a $6 \%$ to $17 \%$ reduction with high levels of all nursing staffing variables.

Moreover, specific studies have examined the influence of staff workload with respect to hospital-acquired staphylococcal infections, both methicillin susceptible and methicillin resistant. In a study conducted in a large neonatal intensive care unit (NICU) in the mid-1970s, the role of overcrowding and understaffing, and their association with recurrent exacerbations of staphylococcal infections, was observed (21). Experiences in other NICUs and other units have confirmed these initial observations (22-24). In an elegant study, Haley et al (25) demonstrated an association between persistent 
understaffing and overcrowding in an NICU and high methicillin-resistant Staphylococcus aureus (MRSA) infection rates by using a measure of intensity-of-care requirements and changes in severity-of-illness case mix. The rate of MRSA infection, adjusted for time- and-intensity-of-care, increased in both intermediate and intensive care areas (rate ratio 1.7; $95 \% \mathrm{CI} 0.10$ to $2.8 ; \mathrm{P}<0.05$ ) after overcrowding and understaffing increased. The rates decreased following the implementation of measures to reduce overcrowding and understaffing. In a study conducted in an adult intensive care unit (ICU), a highly significant correlation was demonstrated between the number of MRSA cases, and the staff to patient ratio and staff to workload ratio (26). With respect to transmission of vancomycin-resistant enterococci (VRE), a positive association was reported between workload utilization, using the GRASP system, and a small VRE outbreak on a medical floor of a Canadian tertiary care institution in 1999 (27). Mean nursing utilization scores were 108.2 before bed closures and rose significantly $(\mathrm{P}<0.001)$ to 121.9 in association with the outbreak, with no changes in mean GRASP scores of 96.8 to 103.1 on a nonoutbreak control ward during the same times. The increasing rates of hospital-acquired Clostridium difficile-associated diarrhea has led to speculation as to whether staff workload increases related to restructuring, coupled with rising rates of hospital antimicrobial usage, may be significant contributing factors (28).

For nosocomial infections, a case control study examining patients in an ICU who developed a central venous catheterrelated blood stream infection revealed that nursing staff reductions below a certain threshold during a period of increased total parenteral nutrition (TPN) use may have contributed to the increase in central venous catheter-related blood stream infections (19). The nurse to patient ratio was found to be an independent risk factor in this study despite controlling for TPN use, assisted ventilation and the period of hospitalization. In a prospective observational study conducted as a before-after analysis, Taylor et al (16) examined the effects of the intense health care restructuring that occurred in Alberta in the mid-1990s on hospital-acquired bloodstream infections. Illustrating to the dramatic changes in Alberta health care delivery during the two time periods studied, there was a $10 \%$ reduction in hospital bed numbers, a $19 \%$ reduction in admissions, a $17 \%$ reduction in patient days, a $25 \%$ increase in TPN days, an increase of the use of central catheters in the ICU by $41 \%$ and a $31 \%$ increase in nosocomial blood stream infections.

Unfortunately, there is a dearth of well conducted studies that have examined the influence and importance of understaffing and overcrowding as risk factors for nosocomial infection and transmission of antimicrobial-resistant pathogens. With the cutbacks and downsizing that are occurring during this era of restructuring in the Canadian health care institutional setting, it is important to evaluate carefully both the sets of staffing levels, and the experience and skill set of the staff regarding the development of these infectious complications. It will also be important for Canadian investigators to examine these changes not only with respect to nosocomial infections but also with repsect to other measures and outcomes related to the quality of care provided within the institutional sector.

\section{REFERENCES}

1. Canadian Healthcare Association. CHA's Framework for a Sustainable Healthcare System in Canada; Discussion Paper. Ottawa: Canadian Institute of Health Information, 1999:1-30.

2. Canadian Institute of Health Information. National Health Expenditure Trends (1975-1999) Report: Executive Summary. Ottawa: Canadian Institute of Health Information, 2000:1-10.

3. Baumgart AJ. Hospital reform and nursing labor market trends in Canada. Med Care 1997;35:OS124-31.

4. Canadian Institute of Health Information. Canada's elderly primary users of hospitals reports Canadian institute for health information. Ottawa: Canadian Institute of Health Information, 2000:1-4.

5. Nicolle LE, Strausbaugh LJ, Garibaldi RA. Infections and antibiotic resistance in nursing homes. Clin Microbiol Rev 1996;9:1-17.

6. Bradley SF. Methicillin-resistant Staphylococcus aureus: long-term care concerns. Am J Med 1999;106(Suppl 5A):2S-10S.

7. Jarvis WR. Preventing the emergence of multidrug-resistant microorganisms through antimicrobial use controls: The complexity of the problem. Infect Control Hosp Epidemiol 1996; 17:490-5.

8. Boyce JM, Opal SM, Chow JW, et al. Outbreak of multidrugresistant Entercoccus faecium with transferable van B class vancomycin resistance. J Clin Microbiol 1994;32:1148-53.

9. Frieden TR, Munsiff SS, Low DE, et al. Emergence of vancomycin-resistant enterococcus in New York City. Lancet 1993;342:490-1.

10. Gold HS, Moellering RCJ: Antimicrobial-drug resistance. N Engl J Med 1996;335:1445-53.

11. Chow JW, Yu VL, Shlaes DM. Epidemiologic perspectives of enterobacter for the infection control professional. Am J Infect Control 1994;22:195-201.

12. Shales DM, Binczewski B, Rice LB. Emerging antimicrobial resistance and the immunocompromised host. Clin Infect Dis 1993;17(Suppl 2):S527-536.

13. Seppala H, Klaukka T, Vuopio-Varkila J, et al. The effect of changes in the consumption of macrolide antibiotics on erythromycin resistance in group A streptococci in Finland. N Engl J Med 1997;337:441-6.

14. Stratton CW, Ratner H, Johnston PE, et al. Focused microbiologic surveillance by specific hospital unit as a sensitive means of defining antimicrobial resistance problems. Diagn Microbiol Infect Dis 1992;15(2 Suppl):11S-8S.

15. Herwaldt LA, Smith SD, Carter CD. Infection control in the outpatient setting. Infect Control Hosp Epidemiol 1998;19:41-74.

16. Taylor GD, McKenzie M, Kirkland T, Buchanan-Chell M, Wiens R. The impact of health care restructuring on noscomially acquired blood stream infections. Can J Infect Dis 2000;11:34-7.

17. Garner JS, Hospital Infection Control Practices Advisory Committee. Guideline for isolation precautions in hospitals. Part I. Evolution of isolation practices. Am J Infect Control 1996;24:24-31.

18. Li J, Birkhead GS, Strogatz DS, Coles FB. Impact on institution size, staffing patterns, and infection control practices on communicable disease outbreaks in New York State nursing homes. Am J Epidemiol 1996;143:1042-9.

19. Fridkin SK, Pear SM, Williamson TH, Galgiani JN, Jarvis WR. The role of understaffing in central venous catheter-associated bloodstream infections. Infect Control Hosp Epidemiol 1996; $17: 150-8$.

20. Needleman J, Buerhaus P, Mattke S, Stewart M, Zelevinsky K. Nurse Staffing and Patient Outcomes in Hospitals. Harvard 
School of Public Health, Final Report for Health Resources Services Administration Contract No. 230-99-0021. February 28, 2001

21. Haley RW, Bregman DJ. The role of understaffing and overcrowding in recurrent outbreaks of staphylococcal infection in a neonatal special-care unit. J Infect Dis 1982;145:875-85.

22. Arnow PM. Allyn PA, Nichols EM, Hill DL, Pezzo M, Bartlett RH. Control of methicillin-resistant Staphylococcus aureus in a burn unit: role of nursing staffing. J Trauma 1982;22:954-9.

23. Mayhall CG, Lamb VA, Gayle WE Jr, Haynes BW Jr. Enterobacter cloacae septicemia in a burn centre: epidemiology and control of an outbreak. J Infect Dis 1979;139;166-71.

24. Denny F, St John MA, Lewis DB, Daniel B. Nosocomial Klebsiella pneumoniae colonization in a neonatal special care unit. Ann Trop Paediatr 1986;6:123-8.
25. Haley RW, Cushion NB, Tenover FC. Eradication of endemic methicillin-resistant Staphylococcus aureus infections for a neonatal intensive care unit. J Infect Dis 1995;171:614-24.

26. Vicca AF. Nursing staff workload as a determinant of methicillin-resistant Staphylococcus aureus spread in an adult intensive therapy unit. J Hosp Infect 1999;43:109-13.

27. Gardam M, McCabe N, Hurn D, Dedier H, Garcia M, Conly J. Association of nursing workload and bed closures on nosocomial transmission of VRE and $C$ difficile. 39th Interscience Conference on Antimicrobial Agents and Chemotherapy. San Francisco, September 26-29, 1999. (Abst 2085)

28. Conly J. Clostridium difficile-associated diarrhea - the new scourge of the health care facility. Can J Infect Dis 2000;11:25-7. 


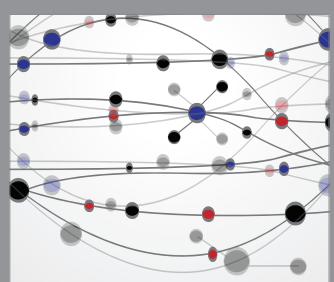

The Scientific World Journal
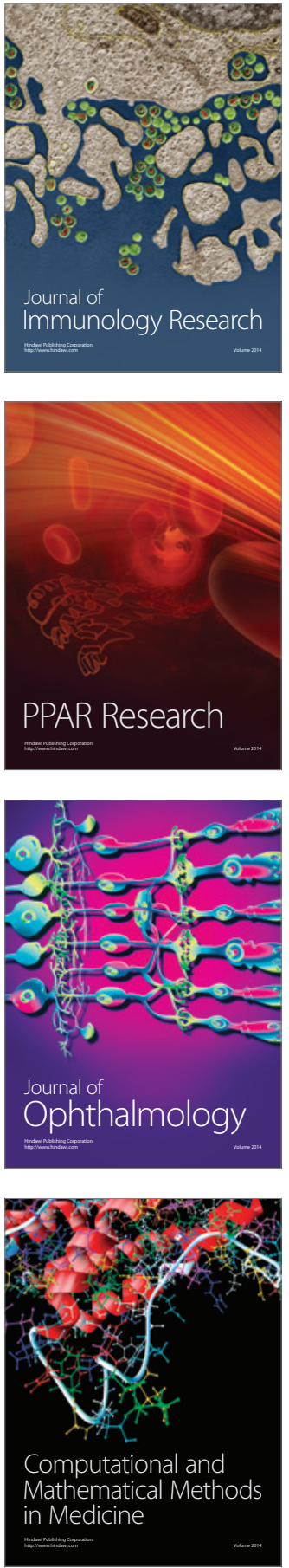

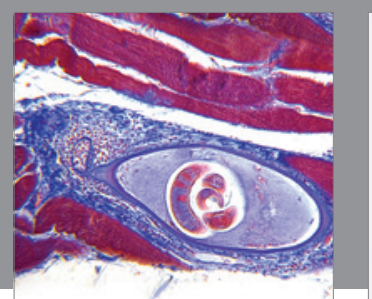

Gastroenterology Research and Practice

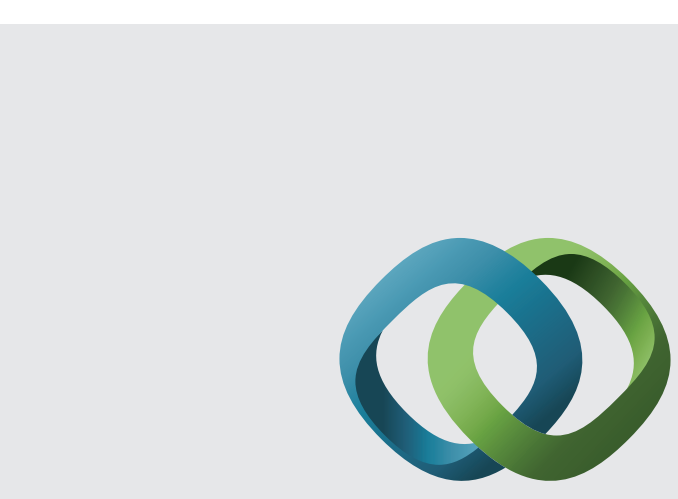

\section{Hindawi}

Submit your manuscripts at

http://www.hindawi.com
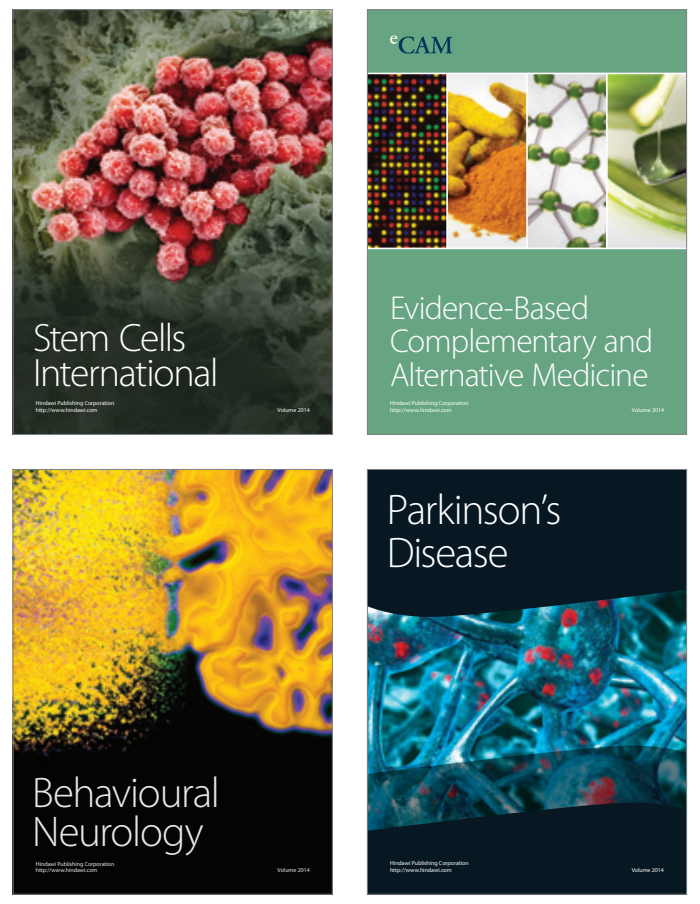
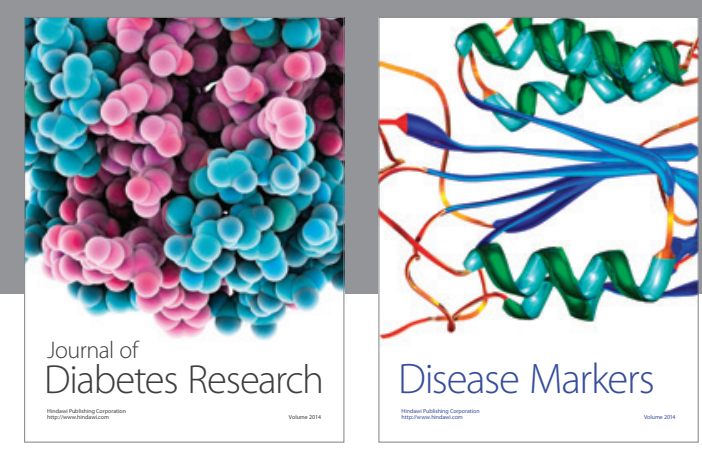

Disease Markers
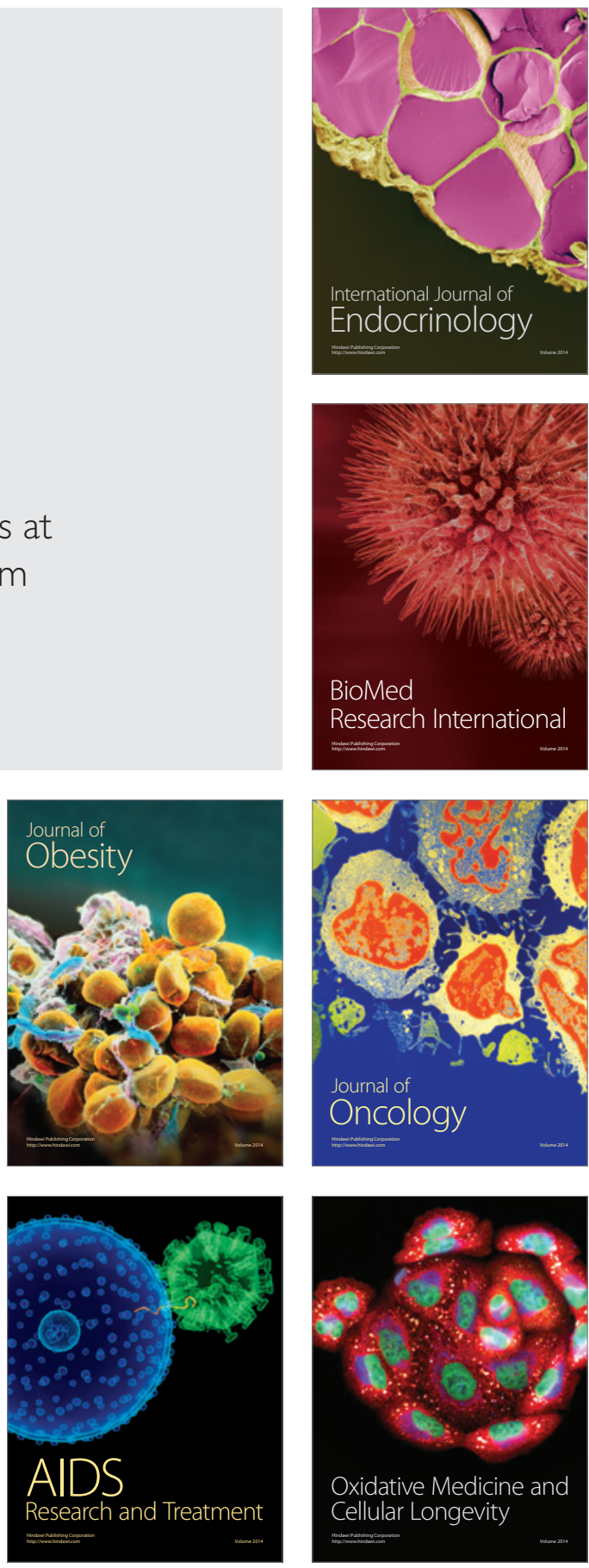